\title{
Open Access Journal of Ophthalmology
}

\section{Festival Related Eye Trauma in India: Causes, Prevention \& \\ Management}

\author{
Suresh K Pandey $1,2,3 *$ and Vidushi Sharma ${ }^{3}$ \\ ${ }^{1}$ Visiting Assistant Professor, John A Moran Eye Center, University of Utah, USA \\ ${ }^{2}$ Visiting Clinical Instructor, Save Sight Institute, University of Sydney, Australia \\ ${ }^{3}$ SuVi Eye Institute \& Lasik Laser Center, C 13 Talwandi, SuVi Eye Hospital Road, Kota, \\ Rajasthan, India
}

*Corresponding author: Suresh K Pandey, President, Kota Division Ophthalmological Society (KDOS), Vice President, Indian Medical Association (IMA) Kota Director, SuVi Eye Institute \& Lasik Laser Center, C 13 Talwandi, Kota, Rajasthan 324 005, India, Tel: +91 9351412449; Email: suresh.pandey@gmail.com

\section{Editorial}

There is no festival or ceremony which is complete in India without fire crackers and fireworks. Unfortunately, so are eye injuries. A large number of ocular injuries are reported every year that are caused due to fire crackers [1]. Many reports have indicated that debris flying in the air due to fireworks and fire crackers play an even major role in these eye injuries than the actual blasts' force. Researchers have highlighted the dangers of these fire crackers and fireworks and studies have narrated the importance of spreading awareness regarding these injuries in order to tackle the increasing cases being reported throughout India.

The most common reason of these injuries is sparklers and bombs, while Roman candles and bottle rockets are close behind [2]. There is another dire cracker which is widely used in India called a 'Bhoo Chakra', which is a spinning fireball, which is also a cause of these eye injuries. Both the individuals lighting these crackers and the bystanders are at high risk of sustaining these injuries [3]. Another cause is the negligence in not lighting the firecrackers properly and not taking safety precautions.

Even if necessary precautions are taken, accidents can happen if the devices experience malfunction or individual attempt to re-ignite the crackers. Moreover, failure of maintaining safer distance when fire crackers are being ignited, lack of parental supervision, and little to no safety measures are also major causes of such accidents [4]. Instead of being lighted in open and safe public areas, people in India light up these fire crackers in streets as well which puts the bystanders at risk.

The fire or heat from the fire crackers can cause serious burns and damage in the eye, around it or in other parts of the body [5]. Moreover, the brutal force through which a foreign object hit the eye factors in the severity of the injury. The type of chemicals used in the fire crackers can also be a cause of these injuries [6]. In many of the cases reported, the eye injuries are caused due to a mixture of these three which causes a lot of damage to the eye and might result in loss of vision [7].

According to published report, $20 \%$ of eye trauma is caused by injuries sustained due to fireworks and fire crackers in the developing countries, making it one of the major reasons of increasing visual disability. The most vulnerable are the children who can lose their vision because of these injuries [8]. It is crucial that ophthalmologists play their part in spreading awareness among their patients and educate them about the importance of safety precautions.

These injuries can be tackled efficiently by first thoroughly cleaning it and then utilizing the appropriate technique depending on the type of injury. For superficial 


\section{Open Access Journal of Ophthalmology}

injuries with intact globe, copious irrigation must be given to ensure foreign particles are removed. It is important to look for any foreign bodies and clean the area vigorously.

In case of penetrating eye injury involving cornea, urgent surgical intervention is required, as well as suitable antibiotic prophylaxis to prevent postoperative endophthalmitis, post-operative steroids. Moreover, it is important to teach the patients about the risk of sympathetic ophthalmia and must be encouraged to immediately report back to the doctor if they experience any symptoms in the other eye.

Aside from taking precautions during surgery, it is important to be aware of the medico-legal implications and the physicians must take a detailed and informed consent from the patients before you begins the surgery. It is essential that you explain in detail all the benefits, complications and other essential factors associated with the surgery.

Furthermore, all of the cases should have careful ocular and retinal evaluation before starting the surgery. In case, the retina isn't visible, it is important to take an ultrasound examination. Other than that a postoperative follow-up is also crucial to be explained to the patient.

In case there are other types of injuries on the body, the right specialist must be referred to immediately in order to provide the right treatment to the patient. Lastly, relevant authorities must be informed if required so that better precautions and guidelines can be taken.

There is no doubt about the fact that fire crackers are used extensively in India during social events, ceremonies and festivals. This is especially true during Diwali, which is one of the most celebrated Hindu mythological events [9]. The usage of firecrackers also results in burns and injuries. As a result, the eye injuries caused by fire crackers during festivities is still one of the major causes of blindness in India. There are numerous ocular cases that occur especially during festive seasons.

There is a strong need to spread public awareness by explaining the causes and prevention of these injuries to reduce these accidents. The public must be encouraged to wear protective eye gear and take other necessary precautions to prevent suffering from ocular trauma, as well as its consequences of blindness and/or visual impairment [10]. Several authors rightfully highlights the importance of spreading awareness and taking safety measures during these festivals. Moreover, there is a dire need for a restrictive legislation on fireworks and crackers in order to decrease the increasingly high rate of ocular injuries in India.

\section{References}

1. See LC (1994) Epidemiology of fireworks injuries: The National Electronic Injury Surveillance System, 1980-1989. Ann Emerg Med 24(1): 46-50.

2. Berger LR, Kalishman S, Rivara FP (1985) Injuries from fireworks. Pediatrics 75(5): 877-882.

3. Tandon R, Agrawal K, Narayan RP, Tiwari VK, Prakash $V$, et al. (2012) Firecracker injuries during Diwali festival: The epidemiology and impact of legislation in Delhi. Indian J Plast Surg 45(1): 97-101.

4. Mishra A, Hasan J (2016) Paediatric Ocular Trauma: A Population Based Study on Ocular Morbidity in Children and Prevention of Monocular Blindness in Cases Attending a Tertiary Care Teaching Hospital. Ann Int Med Den Res 2(3): 99-101.

5. Kumar R, Puttanna M, Sriprakash KS, Sujatha BL, Prabhakaran VC (2010) Firecracker eye injuries during Deepavali festival: A case series. Indian J Ophthalmol 58(2): 157-159.

6. Elangovan S, Rajalakshmi AR, Prabhu R (2016) An analysis of ocular firecracker injuries in five consecutive years during a festive season in a tertiary eye care hospital in South India. Expert Review of Ophthalmology 11 (3): 34-58.

7. Katiyar V, Sonal Bangwal, Sanjiv Kumar Gupta, Vinita Singh, Kumari Mugdha, et al. (2016) Ocular trauma in Indian paediatric population. J Clin Ophthal Res 4(1): 19-23.

8. Smith GA, Knapp JF, Barnett TM, Shields BJ (1996) The rockets' red glare, the bombs bursting in air: Fireworks-related injuries to children. Pediatrics 98(1): 1-9.

9. Negral AD, Thylefors B (1998) The global impact of eye injuries. Ophthal Epidemiol 5(3): 143-169.

10. Mehta D, Sur M, Chintan P, Agrawal AB, Vora HJ, et al. (2004) Fireworks injuries-epidemiology and prevention. Indian J Burns 12(1): 48-50. 